\title{
La Parábola del Retorno
}

\author{
Ala bronca, de noche entenebrida \\ rozó su frente, conmovió su vida \\ y en vastos huracanes se rompió.
}

M ientras los huesos de Porfirio Barba Jacob descienden al fondo de su tierra, su espíritu asciende hasta la superficie de la patria, y cerrando la órbita entra estelarmente a la familia de los inmortales.

La parábola del retorno de estos despojos es el inverso signo del poeta, porque Barba Jacob no ha venido a esta raza sino que ella ha llegado hasta él, $y$, en un instante de infinita revelación de su gracia, escarbó en la tierra lejana y crepitante, donde sus huesos se regocijaban en la gracia de Dios; los amortajó en la urna amorosa y ahora los reintegra al calcio originario, a stus ríos, a sus árboles, para que la densidad de su vida nos revele todo el misterio que ahora conoce.

Cruzados hacia contrarios horizontes hay huesos retorcidos como sus caminos y derechos hacia el corazón de la tierra; diminutas falanges que reconstruirían las más bellas manos patricias y cavidades huecas como aquellos almuédanos olvidados por donde sonó una vez la canción de la vida profunda; y hay también el polvo de su corazón sonoro como una lira en cautiverio y luminoso como una pupila. Ya alcanzó la perfumada vocación floreal de quien dijo que "toda ceniza es polen y su cáliz el cielo".

Proceloso y solitario Porfirio Barba Jacob emerge del seno de este pueblo con el que anduvo espiritualmente por todas las distancias. Hoy vuelve con el labio abolido, viudos los huesos de su carne estremecida, y jubilosamente tendidos hacia la acequia que un día se llevó el treno funeral de su tragedia. Queremos imaginarlo 
ahora, transido de adolescencia, alternando en bucólicas veladas con Juan de Dios y Ricardo, con David y Francisco, atrozmente resignados al destino parroquial de sus nombres pero con el alma abierta al olor del azahar. Con ellos descifró el sentido del árbol y la fruta, del traje y de la nube, de la niñez y la plenitud y vió niñas festivales con el labio impaciente que le llenaron los ojos de aquel estupor rutilante que recuerdan los que le conocieron. Todos teníamos novia, contó, después, ingenuamente el hombre demoníaco y "todos amaban con mi amor las músicas del río".

Aquella era la Antioquia cereal que produjo a Gregorio y a Epifanio, pero entre las espigas y mazorcas blanqueaban ya las primeras chimeneas industriales, mientras las carreteras y los ferrocarriles empezaban a cambiar la geometría del paisaje. Como un naufragio folklórico, en los caminos de arriería se ahogaban los últimos cantares de los campesinos, cayendo río abajo del pasado. Se producía vivencialmente el cosmopolitismo de la raza, transformando sus modos de vida, pero no la vena sentimental y aventurera del pueblo. Todo aquello que el sociólogo y el estadista reducen a concepto Io expresa el poeta por medio de símbolos enamorados y aquel momento constelar de la raza fulge para Barba Jacob en una cabellera rubia que va despidiendo aquel mundo desde el balcón de Shakespeare y de Bécquer mientras la linda hermana Julia sombreaba sus lágrimas debajo de unos ojos que alumbraban la oscura urdidumbre de las serenatas.

La abuela Antioquia estaba podando el huerto en "El solar de los Lulos de Oro", y luchaban en la geografía las formas del alma eglógica que perecía y el alma mecánica que vence. El niño que vivió siempre en Barba se hunde en sí mismo y deja caer palabras como centellas. Es una especie de amor superado éste que sintió él, amando a su patria con un amor amargo. Por eso cuando se produce ya el poeta que crecía en el niño, no asume la actitud de la melancolía sino la de la tragedia. Gregorio había expresado el paisaje físico y social de una Antioquia que espigaba maizalmente su poesía con la reminiscencia virgiliana. Expresaba la conformidad del peón de hacha y carriel, que siembra estróficamente sus veredas, sin ninguna insurgencia perturbadora. Su métrica y su ritmo no ofrecieron la peligrosa novedad y el telón de fondo de su poesía es el melancólico, un estado de incertidumbre resignađa, con adhe- 
sión al mundo externo inmodificable. Barba Jacob, en cambio, introduce una nueva dimensión a aquella actitud, y, a la intensidad de los viejos abuelos de la poesía antioqueña, opone la profundidad que supone el carácter con preferencia al gesto. El Yo, más bien que la naturaleza. $\mathrm{Y}$ por eso si en Gregorio el protagonista de la poesía es el paisaje ante el cual el poeta es un sujeto pasivo del acontecer, en Barba Jacob esa poesía resulta autobiográfica ya que el elemento psicológico que falta en aquélla, entra aquí en forma dramática, en pugnacidad con el universo circundante, sin mesianismo alguno, sino en forma individual y desesperada:

¡Oh!, iquién pudiera de niñez temblando

a un alba de inocencia renacer, pero la vida está acabando

y ya no es hora de aprender!

grita el poeta en el ápice de la suprema angustia, invocando aquel estado en el que el hombre no ha alcanzado a trizar con su conciencia el nivel de la realidad hostilizante.

Ese elemento trágico, esencial a toda lírica, fluye siempre en el hombre cuando se hace turgente sobre la plana conciencia social, afirmándose como carácter personal. Porque aquella angustia de lo trágico no pertenece a la dimensión física de la naturaleza y no salta sino cuando el Yo se hace conciencia y acomete contra las fuerzas externas, hasta que se hunde en su propio seno, así como los aljibes acosados por la fuerza mineral de la montaña buscan una hendija más porosa a la humedad por donde puedan gotear su cristalina presencia.

Al lograr aquella dimensión de profundidad, la poesía se manifiesta biográficamente porque la noción del espacio interior es una conquista de carácter místico que sólo alcanza el hombre cuando desciende hasta su propio fondo holgadamente y encuentra alli la raíz cósmica que lo mantiene conectado al universo:

De simas no sondeadas subía a las estrellas; un gran dolor incógnito vibraba por su acento:

fué sabio en sus abismos, y humilde, humilde, humilde, porque no es nada nada, una llamita al viento...

$\mathrm{Y}$ supo cosas lígubres, tan hondas y letales, que nunca humana lira, jamás, esclareció, $\mathrm{y}$ nadie aún ha medido su trágico lamento... era una llama al viento y el viento la apagó. 
Esa sabiduría de sí mismo es la mayor aventura geográfica de un hombre. Quien la realiza, como Barba Jacob, traza ntievas familias consteladas en los ámbitos del misterio. Por eso nos ofrece, como todo gran poeta, en la contradictoria vastedad de su vida; aquel cristal de aumento que los mortales necesitamos para percibir determinadas relaciones de la naturaleza y su belleza nuclear. $Y$ no se pueden separar su poesía y su vida porque gravitaron ambas sobre un mismo destino, sin deberle a ninguna otra disciplina, el doloroso mensaje que traía su alma. Todo lo que en él era conciencia aparecía forjado en una misma greda lírica, despojado de toda otra aplicación. $\mathrm{Y}$ si no cantó la dulzura de muchas cosas hermosas, que otros han cantado, es porque su obra no pertenece a la fantasía sino a la imaginación, que es la manera más personal de recrear el universo. Fué un poeta del infortunio y el instrumental de su espíritu sólo recogió el viento de la tragedia.

Es que la alegría superficial y tumultuosa puede cantarse con palabras, pero la alegría esencial y profunda no se encuentra sino en el fondo de muchas soledades; por eso necesita acento y ese es el tono que suena en la "Oda a la Alegría" de Schiller. Los músicos, que conocen el ritmo interior de los sonidos; son por la misma tazón, los mejores críticos para este género de poetas. A la vera de su canto parece que los árboles cerraran el párpado de sus hojas y un violoncello lejano difundiera el tema en un scherzo taciturno. Barba Jacob fué un fugitivo de esa euforia en que reverbera el egoísmo y nunca pensó que cada verso suyo fuera subrayado con un golpe de bombo.

Las mismas pasiones no están aquí domesticadas por la inteligencia, sino elevadas hasta la alta temperatura del poema y su mercurio marca la fiebre de humanidad, mucho más por las riberas del corazón que por las glaciales vertientes cerebrales. Filiando su espíritu en el tronco de las grandes genealogías universales hay que situarlo más del lado de Dante que de Petrarca; de Bandelaire que de Mallarmé; de Dostoyerski que de Gogol; de Shakespeare que de John Keats; de Rilke que de Goethe y como Shakespeare, es el abismo iluminado por donde cruzan desesperadamente unidas la ternura y la sordidez, la delgada franja mística y la senstualidad patológica; el hastío y la plenitud, el hombre y la mujer en una espeluznante misa negra de sombría belleza. 
Cuando un hombre así logra descifrar el difuso ambiente, se hace conciencia en el pueblo y convierte en cunas los sepulcros. Algo de Antioquia nace hoy en estas raíces y el pueblo las redime del olvido, reconstruyendo el edificio de su infancia que fué la de todos nosotros, como al hogar hechizado volvemos tras la heroica fatiga. Porque solamente descle el arrecife de la raza alcanzamos el brioso pulso de la ola que nos 1leva hasta aquella intimidad del hombre. $Y$ los pueblos no llegan hasta ellos para juzgarlos sino para comprenderlos porque en el juzgar hay una precavida actitud de arquetipo mental insuficiente para medir la realidad hirviente de estas vidas. El pueblo es el primer contorno con que se encuentra el hombre y cuando aquel contorno se hace derredor ante él es porque ha descubierto un nervio oculto de su propia sensibilidad, produciendo en la confusa melodía de su destino aquel trémolo que es la pulsasación más honda del alma universal sobre un grupo. Ese es el secreto de Barba, sumido en la raza como el tema de las sinfonías en la vasta urdimbre musical de los conjuntos.

Barba Jacob aparece en uno de nuestros más blasonados pueblos que parecen trazados minuciosamente por la mano de un Azorín o de un Baroja que no fuesen fundadores de pluma sino de hacha. Allí podría escribirse sobre el primor de lo provinciano, en un ambiente recoleto y arisco. Situado en una meseta de frigidez vecina al hielo la naturaleza parece recordarle al hombre que no sólo es de tierra, sino también, de niebla. La vegetación apenas breve como para no olvidar nuestras raíces botánicas.

Desde las cañadas sube una densa neblina, borrando la geografía y fundando una evanescente población que llena de fantasmas la inaginación de las almas elegidas. Una luz indirecta da a los bordes de la gasa diversos tonos que oscilan desde el oro metálico hasta el de los terciopelos funerarios. Regiones movedizas van surgiendo a la vista y una reminiscencia polar inunda el horizonte en donde la hosca figura del oso asustó a los conquistadores, peinando el paisaje con sus melenas perturbadoras.

$\mathrm{El}$ fondo de esta naturaleza se hunde hegelianamente en el tipo de la meseta de una vida interior más patética, porque el hombre se produce como una realidad intermedia entre el espíritu y la naturaleza en una faena incesante de absorción vascular por uno u otra. Allí donde la niebla no alcanza a evadirse totalmente del flanco. 
abismal de la montaña la luz trastorna la visión en un vértigo de sugestiones como aquellas en que la mente vacila para descifrar la carne del espíritu. La percepción del mundo allí, para quien logra la evasión, no puede hacerse adecuadamente con sentidos consuetudinarios.

Rodeado por aquel ambiente lácteo el poblado numeroso se dilata en limpias mansiones donde crece uno de nuestros mejores grupos étnicos. Según las propias palabras del poeta, allí: "el cura melifica y amenaza, las madres procrean hijos como la caña de maíz los granos y la civlización es dulzura sin inventos, amor al prójimo sin automóviles, obras de misericordia sin locomotoras, castidad sin cinematógrafo y donde la belleza y el vigor, la salud moral y la esperanza, la inteligencia y la lealtad, son como flores caídas del manto de Jesucristo".

Con variantes más o menos fortuitas allí está el paisaje habitual de nuestros pueblos, sumido en una promisoria actitud de escuchar. Núcleos todavía no desprendidos de la aclimatación ibérica, mentalmente adictos a las formas rurales del espíritu, yacen silenciosos entre una tierra fatigada, en una ebullición sorda, desde la cual se desprende súbitamente una chispa lírica que recuerda a las gentes la dimensión espiritual de la raza. Lo que estamos haciendo ahora, para que "su esfuerzo no sea vano", es procurar que descienda hasta nosotros la lumbre de aquella cándida chispa, recogiendo el efluvio como una noticia de lo que hay en el apretado seno de la piedra.

El oficio semoviente del genio aparece así en la historia de todas las razas con una paradojal y contradictoria vocación navegante. Mientras vive sumergido todavía en la carne, es una fuerza de exclusión porque entra en la marea social, desplazando un tonelaje de prejuicios en la ancha curva de su vida. A lo lejos apenas se divisa el ingenio que lanza desafiadoramente el humo de sus chimeneas, pero al emanciparse del cuerpo, se convierte en una poderosa fuerza de inclusión que hace vivir bajo el mismo meridiano las más protuberantes lejanías.

Particularmente en Barba Jacob se ilumina el contraste social de nuestro pueblo que produce dos estilos de inteligencias: el empresario y el lírico. El primero lo fía todo a la titánica masa, en un esfuerzo desmesurado de atesoramiento geológico que le da un 
ancho pedestal a la organización económica y cierta seguridad inmisericorde al devenir social. Es preciso sutilizar mucho para percibir los matices de su utilidad porque su presencia invade todo el contorno y nos deja pocos resquicios para apreciar cuánto hay de voluntad y cuánto de inercia egoísta; cuánto de azar y cuánto de fatiga silenciosa. Hasta dónde es proceso de integración acaparadora y vegetativa y hacia dónde comienza el ecuador del espíritu.

En cambio el estilo lírico que comprende al artista, al héroe, al pensador y al santo se ajusta a un tipo de hombre casi imperceptible al que tenemos necesidad de mirar atentamente para llevar a la retina toda la riqueza interior de sus líneas. Su presencia no está allí mineralmente como la montaña sino que es un ímpetu perenne que sólo adivinamos por la aplicación del anemómetro. Es una presencia como la del viento, con una generosidad milagrosa que no anula a nadie, ni extingue vida alguna en su contorno sino que, por el contrario, está vivificando gérmenes ocultos, levantando del limo a la clara luz de la conciencia aquellas virtudes amortiguadas que sustraen al hombre de la zoología hacia el espíritu.

Los dos estilos son esenciales para valorar y comprender plásticamente nuestro conjunto racial. Mucho más desde dentro que desde fuera porque sólo percibiéndolos desde dentro lograremos que no se desplace unilateralmente nuestra estimativa. Desde afuera sólo se comete el error de una falta de perspicacia, fatal para el que lo comete únicamente, pero el error desde dentro sepulta inexorablemente las posibilidades de lograr una definitiva síntesis cuya tragedia de formación celebramos hoy, subiendo alpinistamente hasta el ventisquero que hubo en el alma de Barba Jacob.

Por eso Antioquia, al rodear el asilo final de este raro y formidable vástago, consagra cuanto hay de universal y libre en su espíritu. Contra mucha crítica deficiente hay que percatarse de que Barba Jacob no es un poeta regional, sino que, como todo grande hombre, crea su propia especie de espiritualidad universal. Ciertamente, tomó de aquí el ímpetu y la fornida estampa que paseó por inusitados vericuetos de la geografía y del espíritu, pero su obra no pertenece al tiempo, ni al espacio, ni a la sangre que son accidentes tocados de materialidad. Antioquia quizás cumplió con él el destino del yesquero de sus campesinos: lo golpeó con su sentido del orden: con la agria concepción del deber y con la ciega voluntad de vivir 
y produjo en él la gota de fuego contra todo el orden; la dulzura profunda de quien entiende la vida como la superación de vivir y morir y la hostilidad contra toda disciplina.

Como siguiendo el mandato despiadado de Plutarco, Antioquia tributa los honores más útiles a los vivos y los más gloriosos a sus muertos. En el fondo se da cuenta de que los pueblos no viven de las riquezas acumuladas por los antepasados, ni de sus afanes expansionistas, ni del lucro incesante, sino del espíritu que sus hombres sembraron en las orillas de su historia. $\mathrm{Y}$ si aparece pródiga en los honores a los que han forjado su predominio material es necesario reconocer que son fugaces estímulos que desaparecen con el afortunado porque su nombre se extingue velozmente en la conciencia reflexiva de sus muchedumbres. En cambio, el tardío reconocimiento a aquéllos altos varones que, sin agregarle un ápice al poderío material, colonizaron vastas comarcas de la inteligencia o de la sensibilidad, tiene un sello de virtud imperecedero, supone una diaria presencia de espejo porque conoce que "la vida no es sueño sino que debe convertirse en sueño".

Cuenta un egregio escritor este ingenuo y luminoso episodio final de Barba Jacob: "A las dos de una fría madrugada, unos músicos colombianos entraron al sanatorio para darle al poeta moribundo una serenata. Entre las sábanas, como en un desierto paisaje de frío, se ponía el sol de la poesía colombiana. A los primeros acentos del bambuco: "Van cantando por las sierras - con honda melancolía - unos cantos de mi tierra- cuando va muriendo el día'su rostro ya tocado por las sombras revivió como si en los glaciares de su lenta agonía hubieran resplandecido todas sus auroras boreales, o como si su niño regresado se hubiese convertido en un florecido arrayán con mirlas y estrellas.

"Alguien lo sostenía, incorporado sobre los almohadones mientras recibía la milagrosa trasfusión de patria que lo mantuvo sereno y claro hasta la muerte y dijo: 'Esas manos de los míos i cómo tocaban, cómo cantaban!... Si yo hubiera tenido sus manos y hubiera vivido en los tiempos de Salomón hubiese tañido la tiorba o el salterio...’ ¿Cómo te sientes Barba?, le preguntó un amigo, 'Me siento como si reposara en el fondo de una perla', respondió el moribundo." 
Repose así en la memoria de éste su pueblo que es como una perla dura contra el tiempo, luminosa como su canto, brillando su oriente hacia la inagotable cruz de sus mayores. Rodeando su límpido destello vivirá su pueblo desde ahora, presidido por los más egregios conductores de la patria colombiana y con la vigilante pupila de los hermanos de su espíritu que traen a esta orilla de misterio el recuerdo de la patria hospitalaria donde el poeta conoció el amor y la muerte.

Esa dorada plenitud de la perla que fué el poema inédito cle su agonía, purificada en el final sacrificio, regrese temblando al solar de su infancia que todavía se recata "bajo frondas umbrías; que tuvo un cauce, un roble, zuribios y pomar".

iSeñor, nos hace falta tu música cordial!

Abel Naranjo Viliegas 
